\title{
Design and Construction of a Device for Free Form Surfaces 3D Reconstruction Using Microsoft Kinect
}

\author{
Dr. Tahseen F. Abbas ${ }^{1}$, Dr. Ali Abbar. Khleif ${ }^{2}$, Dr. Hameed S. Ismael ${ }^{3}$
}

${ }^{* 1}$ Production and Metallurgy Engineering. Department, University of Technology-Iraq, Baghdad Iraq ${ }^{2}$ Production and Metallurgy Engineering Department, University of Technology-Iraq, Baghdad Iraq

${ }^{3}$ Civil Engineering Department, University of Technology-Iraq, Baghdad Iraq

\section{ABSTRACT}

There is an increasing need for geometric 3D reconstruction models in the Reverse engineering which is ones of computer Vision applications, reconstruction from a sequence of 2D images is much cheaper than 3D scanners and coordinate measurement machine and also been able to take advantage of the developments in digital cameras and the increasing resolution and quality of images. This work aims to develop a concept of 3D free form surface reconstruction rig and generate the dimension of the surface depending on proposed image processing technique. Through the results obtained is observed that. The overall of calibration accuracy the Root mean square (RMS) value of the point was produced the residuals value in the image space was $(0.2830$ $\mathrm{mm})$ in the IR images.

Keywords : Range Camera, IR Sensor, Stepper Motor, Imaging, Arduino and Matlab

\section{INTRODUCTION}

Reverse Engineering (RE) plays a fundamental role in industrial Computer Aided Engineering systems (CAE). With RE, objects can be digitized, three dimensional (3D) reconstructed and assimilated as computerized models. Digitizing systems in RE are founded on three major technologies
a) Coordinate measuring machines (CMMs).
b) 3D laser scanners.
c) Digital photogrammetry systems.

A. A contact measuring instrument such as plumbline is used. Since this method is adequately strong and accurate, it is generally used to sample points as part of the RE process. However, its advantages are highly diminished by the slow rate of data taking. In increased, the object's surfaces may be superfine or adaptable and require non-contact measurement . Figure (1-1) illustrate a coordinate measuring machine..

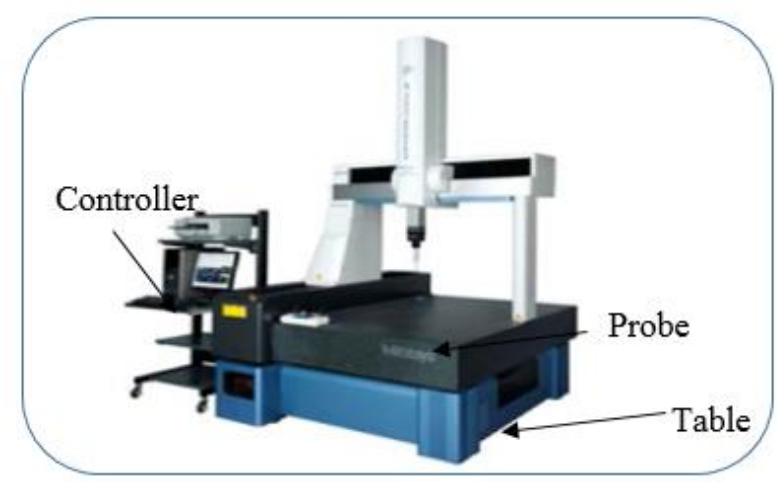

Figure 1: CMM [1]

B. Laser-based range sensors are non-contact sensors and therefore are very rapid. The scanned data give straightforward $3 \mathrm{D}$ points from that a $3 \mathrm{D}$ model can be reconstructed. However, the 3D data generated by 3D laser scanners is not appropriate for direct integration in CAD systems: the scanned data is irregular and sprinkled and requires heavy processing in order to rebuild the 
surface of the object. Laser scanner systems provide a massive amount of digitized point data, therefore requiring a time- exhaustion data lowering process. In order to get better 3D reconstruction processing, some scanned systems provide range image instead of scattered points. A sampled surface $(\mathrm{z})$ function of (xy) is represented as a $3 \mathrm{D}$ image where each pixel contains a height $[1,2]$. Figure (1-2) illustrate a laser scanning.

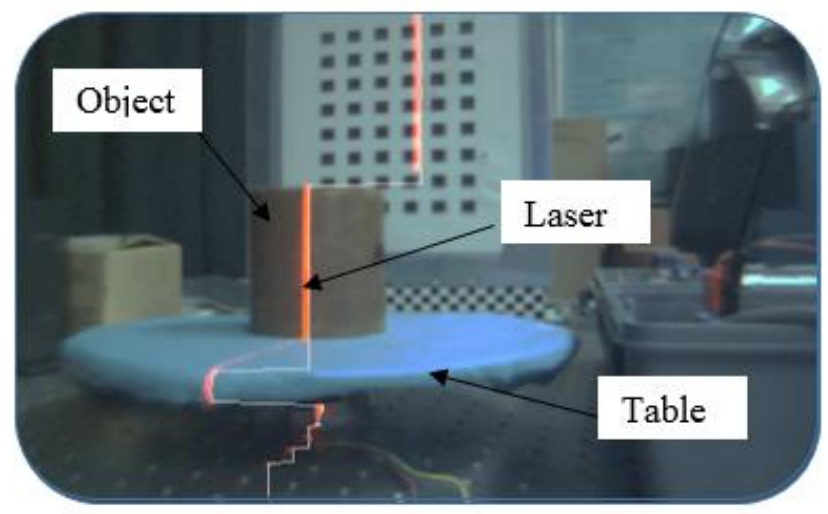

Figure 2: Laser scanner [2]

\section{Digital Photogrammetry Systems}

3D models are reconstructed from an arrangement of 2D pictures. Utilizing a triangulation strategy, the scope of focuses in the scene can be figured by applying a coordinating procedure. This procedure, in any case, is tedious and experiences merging issues. The data is not finished since a few focuses are not "seen" in both pictures. In addition, when different pictures are utilized, camera adjustment is expected to rectifying geometric mistakes and to representing the camera parameters. PC vision procedures can be connected to range of images alone to gather geometric and topological structure, yet precision issues happen on the limits $[1,4]$.

\section{EXPERIMENTAL WORK}

In this proposed $3 \mathrm{D}$ reconstruction technique the shape and dimension of the lasted object are captured and separated with a specific end goal to get duplicate of the same objects and creating information that can be utilized for several engineering applications.

The Adopted rig included implementation of measurement rig based on image processing technique to get measured data of the existing objects The calculated circular path of specific camera and definite the distance between the engineering part who want to measure and the camera are main items to be studied to have accurate results with assume the other parameters are constant like lighting system. The measurement system was built, and some parts were manufactured in this work. After system assembly, tests and calibrations were carried out to obtain the system performance and results. Figure (11) illustrate the Adopted rig.

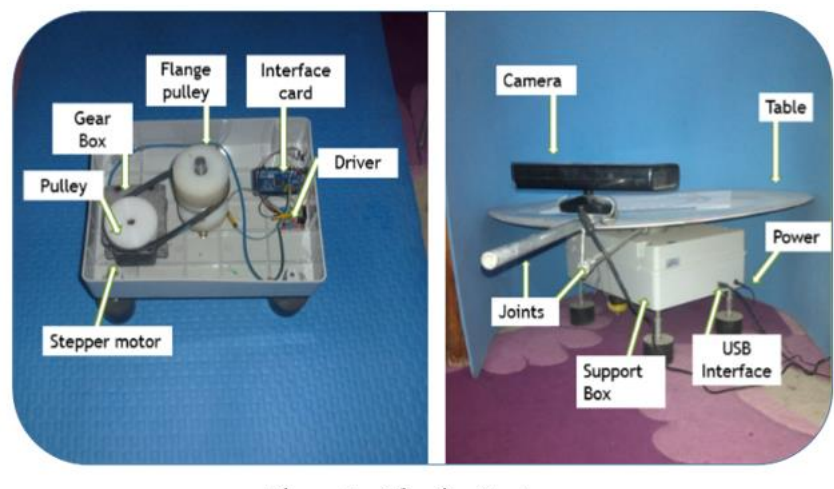

Figure 3: Adaptive System

\section{IMPLEMENTED THE RIG}

The adopted rig consist of asset of subsystems and there subsystems in turn consist of a set of parts as illustrated in figure (1-2).

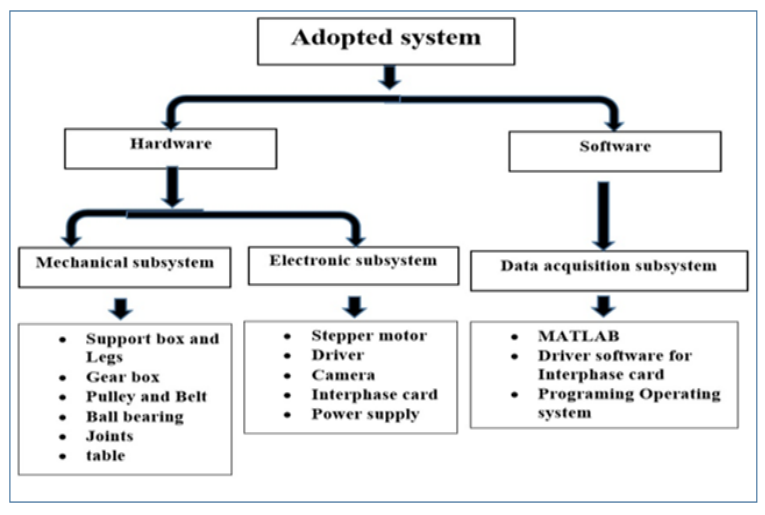

Figure 4: adopted instrument parts

A. Code for rig operation 
The block diagram shown in Figure (4) illustrate the steps of programs work

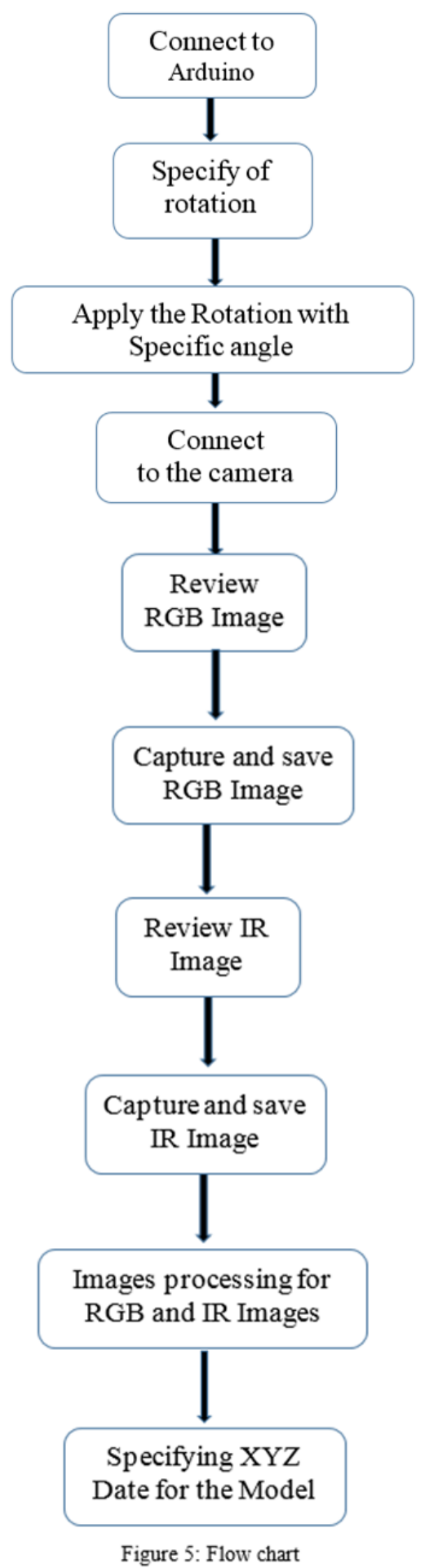

IV. RESULTS AND DISCUSSION
An accurate stepped objected has been machined using CNC milling machine with predefined dimension to be used as a tested object to calibrate the adoptive instrument. Figure (1-4) illustrated the tested object front and side view of the tested first part

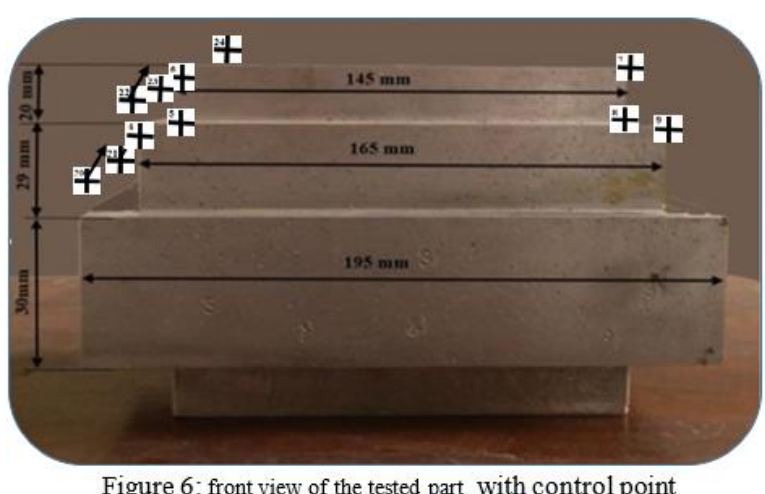

Table 1. Control Point of the First Tested Part

\begin{tabular}{|r|l|l|l|}
\hline CP & $\mathrm{X}(\mathrm{mm})$ & $\mathrm{Y}(\mathrm{mm})$ & $\mathrm{Z}(\mathrm{mm})$ \\
\hline 1. & 100 & 100 & 100 \\
\hline 2. & 100 & 130 & 100 \\
\hline 3. & 115 & 130 & 115 \\
\hline 4. & 115 & 159 & 115 \\
\hline 5. & 125 & 159 & 125 \\
\hline 6. & 125 & 179 & 125 \\
\hline 7. & 170 & 179 & 125 \\
\hline 8. & 170 & 159 & 125 \\
\hline 9. & 180 & 159 & 115 \\
\hline 10. & 180 & 130 & 115 \\
\hline 11. & 295 & 130 & 100 \\
\hline 12. & 295 & 100 & 100 \\
\hline 13. & 295 & 100 & 195 \\
\hline 14. & 295 & 130 & 195 \\
\hline 15. & 180 & 130 & 180 \\
\hline 16. & 180 & 159 & 180 \\
\hline 17. & 170 & 159 & 170 \\
\hline 18. & 170 & 179 & 160 \\
\hline 19. & 100 & 100 & 195 \\
\hline 20. & 100 & 130 & 195 \\
\hline 21. & 115 & 130 & 180 \\
\hline 22. & 115 & 159 & 180 \\
\hline 23. & 125 & 159 & 170 \\
\hline 24. & 125 & 179 & 170 \\
\hline & & 7 & \\
\hline & & \\
\hline
\end{tabular}

Table 2 
listed the RMS value of each IR images of first tested part, and figure (7) indicates the residual value in all capturing IR images of the first part.

\begin{tabular}{|r|l|l|}
\hline \multicolumn{1}{|l|}{$\begin{array}{l}\text { Image } \\
\text { No. }\end{array}$} & angle $(\circ)$ & RMS (mm) \\
\hline 1. & $0 \circ$ & 0.0057 \\
\hline 2. & $45^{\circ}$ & 0.0048 \\
\hline 3. & $90 \circ$ & 0.1216 \\
\hline 4. & $135^{\circ}$ & 0.1690 \\
\hline 5. & $18 \circ^{\circ}$ & 0.4700 \\
\hline 6. & $225^{\circ}$ & 0.0339 \\
\hline 7. & $27 \circ^{\circ}$ & 0.1735 \\
\hline 8. & $315^{\circ}$ & 0.3906 \\
\hline
\end{tabular}

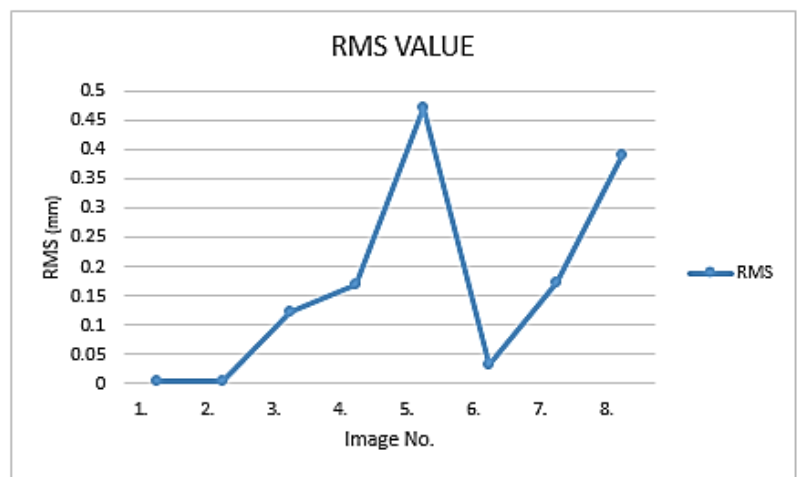

Figure 7: The Residuals value in all capturing $\mathbb{R}$ images of the first tested part

Through the results obtained is observed that .The overall of calibration accuracy the Root mean square (RMS) value of the point was produced the residuals value in the image space was $(0.2830 \mathrm{~mm})$ in the IR images. that is mean the error in $3 \mathrm{~d}$ reconstruction was $(0.2830 \mathrm{~mm})$ in total length.

\section{CONCLUSION}

3D models Reconstructing from existing part is a prime issue in numerous computer vision research like Pattern recognition, Reverse engineering and Industrial investigation. The automatic instrument for creating 3D models was implemented. In this 3D Reconstruction technique the shape and dimension of object are captured and separated with a specific end goal to get a duplicate of the same part in this manner creating information that can be utilized for CAD/CAM purposes.

From the results of this research the following most conclusions can be listed.

1. The adapted $3 \mathrm{D}$ reconstruction instrument is a low cost portable compound Comparison with not portable alternative expensive laser scanners (LS) and Coordinate measuring machines (CMMs) in 3D reconstruction and measurement application

2. The cloud point of the properly was calibrated Kinect sensor camera did not contain large systematic errors.

3. The IR camera didn't effect with how much light in room when the captured images hence the $3 \mathrm{D}$ reconstruction and measurement instrument work in any condition didn't required tough light condition and we could classified the images

4. The value of error of depth data measurements has been increases quadratic with increasing distance from the camera.

5. The $3 \mathrm{~d}$ reconstruction instrument didn't effect with how much Wight of the object because the table didn't have any movement

6. There is limitation of the object size for this instrument the size should not exceed $500 \mathrm{~mm}$ circle diameter

7. 7. The density of extracted points would be decreases with increasing the distance to the camera. It is influencing factor of the depth image resolution.

\section{REFERENCES}

[1]. A. Manor and Affiliated "Reverse Engineering of 3D Models Based on Image Processing and 3D Scanning Techniques" 2001 
[2]. R. j. Hocken \& Paulo H. Pereira "Coordinate measurement Machines Systems" Second Edition by CRC Press Reference 2011.

[3]. D. Huang, G. Lee and D. Yang "3D LASER SCANNER” Final Report for ECE 445, Senior Design, 2013.

[4]. M. Kasser and Y. Egels "Digital Photogrametry" taylor \& Francis ,2002

[5]. F. S. A. Al-hasoon "Accuracy Assessment Of Data Processing In Analytical Digital Photogrammetry Using Relative \& Absolute Orientation Mathmatical Model”,2015

[6]. C. Shu and G. Roth "ree-Form Surface Reconstruction from Multiple Images”,2003

[7]. T. F. Abbas and A. A. Ebraheem "Reconstruction of free form Surfaces in Reverse Engineering Technology Applications"2014

\section{Cite this article as :}

Dr. Tahseen F. Abbas, Dr. Ali Abbar. Khleif, Dr.Hameed S. Ismael, "Design and Construction of a Device for Free Form Surfaces 3D Reconstruction Using Microsoft Kinect", International Journal of Scientific Research in Science and Technology (IJSRST), Online ISSN : 2395-602X, Print ISSN : 2395-6011, Volume 6 Issue 2, pp. 82-86, March-April 2019.

Available at doi :

https://doi.org/10.32628/IJSRST19629

Journal URL : http://ijsrst.com/IJSRST19629 